\title{
Complete urorectal septal malformation with left hemimelia in a neonate: an uncommon association
}

\author{
Gurujala Mahadeva Ramya, ${ }^{1}$ Thangaraj Abiramalatha (ㄷ) , \\ Umamaheswari Balakrishnan, ${ }^{1}$ Saishalini Chinnathambi Narayanan²
}

${ }^{1}$ Neonatology, Sri Ramachandra Institute of Higher Education and Research, Chennai, Tamil Nadu, India

${ }^{2}$ Pathology, Sri Ramachandra Institute of Higher Education and Research, Chennai, Tamil Nadu, India

\section{Correspondence to} Dr Thangaraj Abiramalatha; abi_paeds@yahoo.com

Accepted 10 March 2021
D) Check for updates

(c) BMJ Publishing Group Limited 2021. No commercial re-use. See rights and permissions. Published by BMJ.

\section{To cite: Ramya GM,} Abiramalatha T, Balakrishnan U, et al. BMJ Case Rep 2021;14:e241423. doi:10.1136/bcr-2020241423

\section{DESCRIPTION}

The baby boy was born to a 27-year-old primigravida mother at 33 weeks' gestation with a birth weight of $1800 \mathrm{~g}$. Parents were non-consanguineous. The mother conceived spontaneously and did not undergo any antenatal sonography. The baby was delivered vaginally. $\mathrm{He}$ cried immediately after birth, and delayed cord clamping for $1 \mathrm{~min}$ was performed. At $1 \mathrm{~min}$ of life, the baby became apnoeic and floppy, required positive pressure ventilation followed by intubation. The baby did not maintain saturation even with high pressures of $30 \times 7$ and $100 \%$ oxygen.

On examination, the baby had tapering left leg with absent ankle and foot, aphallia with welldeveloped scrotum and right palpable testis, imperforate anus, single umbilical artery and bilateral elbow contractures (figure 1). He did not have facial dysmorphism. Abdominal sonography showed bilateral multicystic dysplastic kidneys. Cranial sonography was normal. Chest radiograph showed bilateral white-out lungs. Babygram showed sacral agenesis and absent left fibula (figure 1). The baby succumbed at 3 hours of life due to severe respiratory failure. At autopsy, the baby was found to have common cloaca, bladder agenesis and bilateral multicystic dysplastic kidneys, atrophic left testis and hypoplastic lungs in saccular stage of development (figures 2 and 3). There was no history

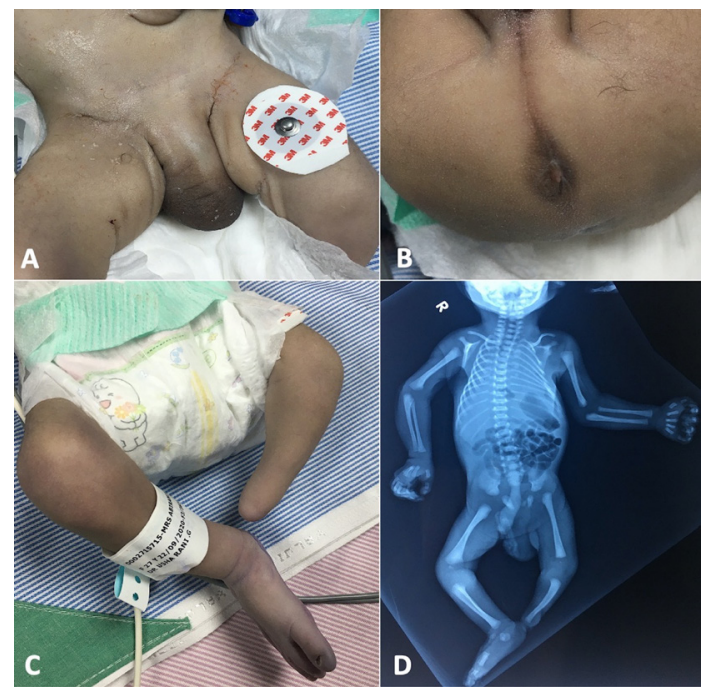

Figure 1 Clinico-radiological images of the baby showing (A) aphallia; (B) imperforate anus; (C) left hemimelia with absent ankle and foot; (D) infantogram showing sacral agenesis and absent fibula.

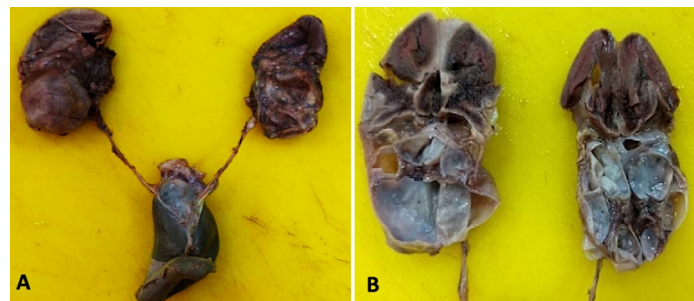

Figure 2 Gross pathology images at autopsy. (A) Bilateral ureters opening into common cloaca; (B) cut section of kidneys showing bilateral multicystic dysplastic kidneys.

of maternal infections or drug exposure during the antenatal period. Considering the low yield of genetic investigations, ${ }^{1}$ we did not do a detailed genetic evaluation.

Urorectal septal malformation (URSM) is a sequence of embryological defects that occurs due to failure of migration and/or fusion of urorectal septum with cloacal membrane. ${ }^{2}$ Complete URSM sequence is characterised by absence of both urethral and anal openings, has a poor prognosis and long-term survival is unlikely. Partial URSM sequence has a common cloaca that drains into a single perineal opening, has better prognosis and long-term survival is well described. ${ }^{3}$ Our baby had

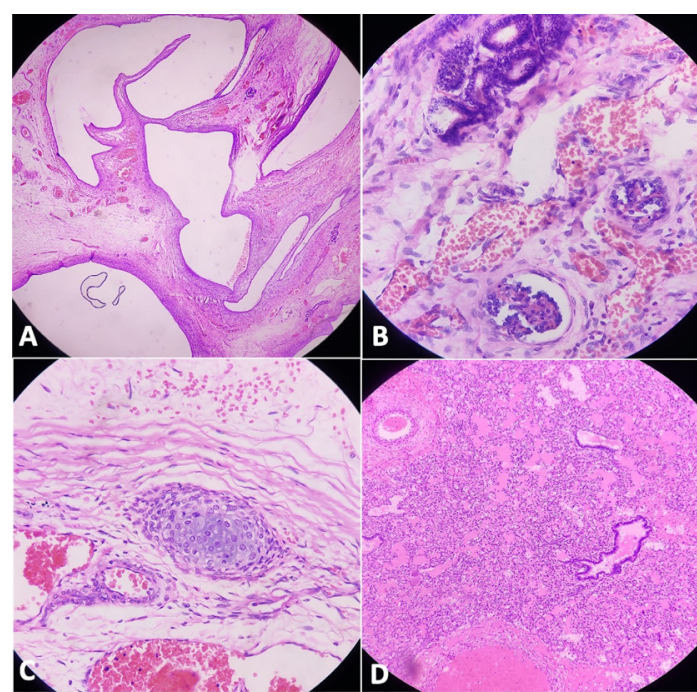

Figure 3 Histopathological images (H\&E stain) showing (A) (10x) multiple cysts in renal parenchyma; (B) (40x) abortive glomeruli and tubules; (C) (40x) cartilagenous areas in renal parenchyma; (D) (10x) severe pulmonary hypoplasia with lungs in saccular stage of development. 


\section{Learning points}

In a neonate who cries well at birth and requires significant resuscitation later, we should consider severe pulmonary hypoplasia as the aetiology rather than perinatal asphyxia or neuromuscular disorders.

- Delayed cord clamping has the potential to promote transition at birth in infants with pulmonary hypoplasia.

- Hemimelia with absent fibula is a rare association with urorectal septal malformation sequence.

complete URSM, since both the urethral and anal openings were absent. Major features include malformations of renal, genital and gastrointestinal systems. Associated features that have been described are cardiac, pulmonary, spine and brain malformations. Though skeletal anomalies are known in babies with URSM, ${ }^{45}$ hemimelia with absent fibula has not been reported. Most of the reported cases of URSM were sporadic, and genetic evaluation was found to be futile. ${ }^{1}$

The baby cried at birth and had breathing efforts until 1 min of life, following which he became apnoeic and required prolonged resuscitation. This was probably due to severe pulmonary hypoplasia. In lambs with diaphragmatic hernia and pulmonary hypoplasia, Kashyap et al showed that delayed cord clamping improved pulmonary blood flow and resulted in better cerebral oxygenation. ${ }^{6}$ In our baby, delayed cord clamping would have sustained placental circulation, gas exchange and oxygenation during the first minute of life. The baby would have become hypoxic and apnoeic later due to hypoplastic lungs and impaired gas exchange. We would like to highlight that in infants who cry at birth and require significant resuscitation later, we should consider pulmonary hypoplasia as the aetiology rather than perinatal asphyxia or neuromuscular disorders. Delayed cord clamping has the potential to promote cardiopulmonary transition at birth in infants with pulmonary hypoplasia.

Contributors GMR conceptualised the case report, performed literature review and drafted the manuscript. TA conceptualised the case report, performed literature review, and critically reviewed and revised the manuscript. She will be the guarantor. UB and SCN performed literature review and critically reviewed and revised the manuscript. All authors were involved in the clinical management of the baby.

Funding The authors have not declared a specific grant for this research from any funding agency in the public, commercial or not-for-profit sectors.

Competing interests None declared.

Patient consent for publication Patient/guardian consent was obtained for publication.

Provenance and peer review Not commissioned; externally peer reviewed.

\section{ORCID iD}

Thangaraj Abiramalatha http://orcid.org/0000-0001-9125-3510

\section{REFERENCES}

1 Aggarwal S, Phadke SR. Recurrence of urorectal septum malformation sequence spectrum anomalies in siblings: time to explore the genetics. Am J Med Genet $A$ 2013;161A:1718-21.

2 Escobar LF, Weaver DD, Bixler D, et al. Urorectal septum malformation sequence. Report of six cases and embryological analysis. Am J Dis Child 1987;141:1021-4.

3 Wheeler PG, Weaver DD. Partial urorectal septum malformation sequence: a report of 25 cases. Am J Med Genet 2001;103:99-105.

4 Jain D, Sharma MC, Kulkarni KK, et al. Urorectal septum malformation sequence: a report of seven cases. Congenit Anom 2008;48:174-9.

5 Shah K, Nayak SS, Shukla A, et al. Spectrum of urorectal septum malformation sequence: a report of eight cases. Congenit. Anom 2016;56:119-26.

6 Kashyap AJ, Hodges RJ, Thio M, et al. Physiologically based cord clamping improves cardiopulmonary haemodynamics in lambs with a diaphragmatic hernia. Arch Dis Child Fetal Neonatal Ed 2020;105:18-25.

Copyright 2021 BMJ Publishing Group. All rights reserved. For permission to reuse any of this content visit

https://www.bmj.com/company/products-services/rights-and-licensing/permissions/

BMJ Case Report Fellows may re-use this article for personal use and teaching without any further permission.

Become a Fellow of BMJ Case Reports today and you can:

- Submit as many cases as you like

- Enjoy fast sympathetic peer review and rapid publication of accepted articles

- Access all the published articles

- Re-use any of the published material for personal use and teaching without further permission

Customer Service

If you have any further queries about your subscription, please contact our customer services team on +44 (0) 2071111105 or via email at support@bmj.com.

Visit casereports.bmj.com for more articles like this and to become a Fellow 